\title{
An analysis of papers published in Environmental Pollution in 2006: A continuing pattern of advancement and success
}

\author{
Yong-Guan Zhu ${ }^{\mathrm{a}, *}$, Zhong-Cheng Wang ${ }^{\mathrm{a}}$, William J. Manning ${ }^{\mathrm{b}}$ \\ ${ }^{a}$ Research Center for Eco-environmental Sciences, Chinese Academy of Sciences, 18 Shuangqing Road, Beijing 100085, China \\ ${ }^{\mathrm{b}}$ Department of Plant, Soil and Insect Sciences, University of Massachusetts, Amherst, MA 01003-9320, USA
}

Received 9 August 2007; accepted 19 August 2007

The journal Environmental Pollution was founded in 1970 and has a long and rich history in publishing papers about the nature, distribution and ecological effects of pollutants in air, soil and water environments. Papers include findings from original research projects, re-examination and interpretation of existing data and reviews of important issues. Commentaries and letters to the editor are encouraged. The journal's impact factor has been steadily increasing since 1998 . The journal's impact factor in 2000 was 1.121 . By 2003, the impact factor had increased to 2.002. In 2004, the impact factor was 2.205, increasing to 2.451 in 2005 . The current impact factor for the journal is 2.769. Environmental Pollution is currently ranked number 14 out of 144 journals in the category Environmental Sciences.

In 2006, Environmental Pollution published 433 papers, among which 424 were primary research papers with five authoritative reviews. In terms of the geographical distribution of the contributions (Fig. 1), USA contributes the most with a total number of 85 , followed by the UK (England + Scotland) with 70 papers, and then China with 65 papers. Other countries that contribute significantly to Environmental Pollution in 2006 are Spain, France, Germany, Canada, Belgium, Italy and Japan. The above-mentioned countries contributed roughly $95 \%$ of the papers published in Environmental Pollution in 2006.

If these contributions are ranked based on individual institutions (Table 1), Chinese Academy of Sciences is right on the top with total number of 27 papers, followed by the Spanish National Research Council with total number of 14 papers. Among the universities, Lancaster University in England contributed the most number of papers (10), followed by Universities of Bordeaux 1, Ehime, Antwerp, Massachusetts and

\footnotetext{
* Corresponding author.

E-mail address: ygzhu@mail.rcees.ac.cn (Y.-G. Zhu).
}

Amsterdam (seven papers from each university). Among the top 25 institutions, five are from China, three from USA.

Individual authors can also be ranked based on the number of publications in Environmental Pollution in 2006 (Table 2). Dr M. Mench from France and Dr S. Tao from China are on the top with seven papers published in Environmental Pollution in 2006, there are 19 authors publishing more than four papers in Environmental Pollution in 2006, and six of them are from China.

Papers published in 2006 covered most areas of Environmental Pollution research, and it is difficult to generalize the pattern of topics among the papers, therefore we used the criteria of $>4$ citations through the database of ISI (accessed on 27, May 2007) to analyze the publication pattern. Altogether there were 20 papers published in 2006 having citation $>4$, among them, seven papers were on aquatic environment, seven papers dealing with soil-plant systems, three papers on air pollution, one on human health, and one on ecosystem health.

Persistent organic pollutants (POPs) are among the popular topics for soil, water and air pollution research, including organohalogen chemicals such as brominated flame retardants, organochlorine compounds (eg. Thomas et al., 2006; Jaspers et al., 2006). Studies on POPs include regional survey of contamination levels, distribution of POPs in different environmental and biotic components, toxicological assessment and remediation technologies. For aquatic ecosystem studies, much of the attention was focused on the bioaccumulation of POPs and metals in the food chain and its potential health and ecological impacts. For example, Jaspers et al. (2006) investigated the levels, patterns and tissue distribution of brominated flame retardants in aquatic and terrestrial predatory birds of Belgium. Isosaari et al. (2006) reported the concentrations of dioxins and dioxin-like compounds in edible fish caught from the Baltic Sea and lakes in Finland.

For soil pollution research, heavy metals remain as an important subject, covering topics of bioavailability, 


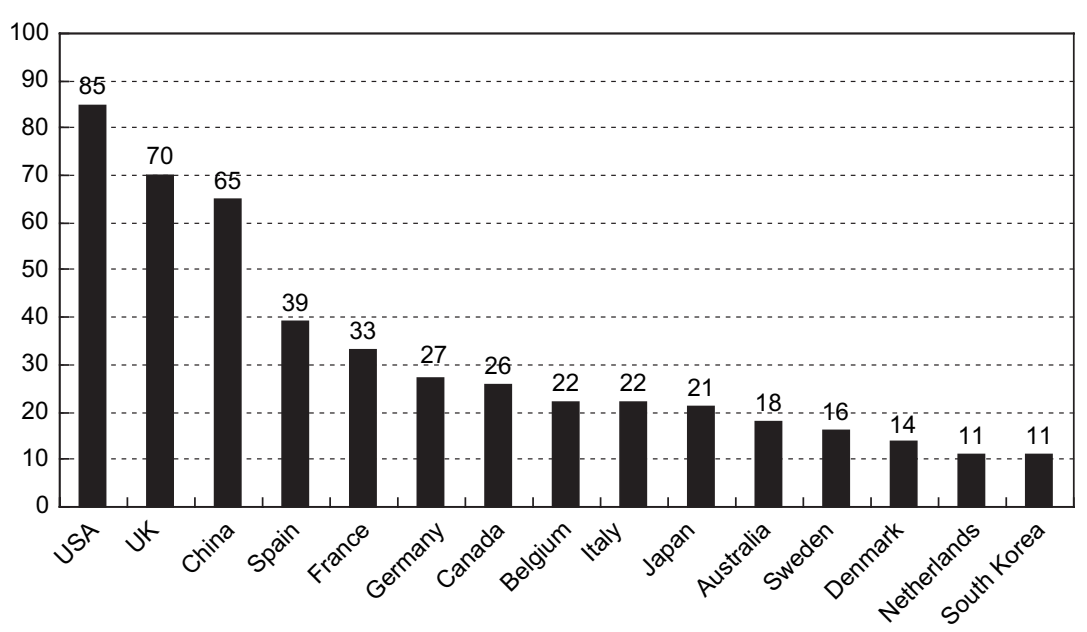

Fig. 1. Country breakdown of contributions to Environmental Pollution in 2006.

ecotoxicology, hyperaccumulation and restoration. Among the 433 papers published in 2006 , there were over 180 papers related to "soils". Soil toxicity tests have been conducted on various endpoints, such as plant, earthworm, collembolan, microbes and humans (Skovlund et al., 2006; Mench et al., 2006; Ren et al., 2006). Remediation of contaminated soils is wide interest, and is an important topic for Environmental Pollution in 2006. Understanding the soil-plant interactions is key towards remediation and restoration of contaminated land. Vogel-Mikus et al. (2006) examined the role of arbuscular mycorrhizal fungi in re-vegetation of metal-contaminated soils. Similar papers have also been published by Regvar et al. (2006) and Leung et al. (2006). Other aspects of

Table 1

Ranking of institutions contributing to Environmental Pollution in 2006

\begin{tabular}{lll}
\hline Number of papers & Institution & Country \\
\hline 27 & Chinese Academy & China \\
& of Sciences & \\
14 & CSIC & Spain \\
10 & University of Lancaster & UK \\
9 & Environment Canada & Canada \\
8 & University of Bordeaux 1 & France \\
7 & Ehime University & Japan \\
& Peking University & China \\
& University of Antwerp & Belgium \\
& University of Massachusetts & USA \\
& Vrije University Amsterdam & Netherlands \\
& City University & China \\
6 & of Hong Kong & \\
& Hong Kong & China \\
Baptist University & \\
& INRA & France \\
& University of Florence & Italy \\
& Zhejiang University & China \\
& Auburn University & USA \\
& Masaryk University & Czech Republic \\
& National Environmental & Denmark \\
5 & Research Institute & \\
Rothamsted Research & UK \\
& Seoul National University & Korea \\
& University of California Davis & USA \\
University of Ghent & Belgium \\
\hline & & \\
& & \\
& &
\end{tabular}

environmental remediation including the use of amendments have also been well represented in 2006.

Altogether there were 58 papers published in Environmental Pollution in 2006 that were related to air pollution, and roughly there were two major topics, one on the impacts of ozone on terrestrial ecosystems, and the other on particulate matters and toxic compounds that reside on these particles. Air sampler for persistent organic pollutants is by far the most popular topic in 2006, this is could be sue the publication of a special issue on this topic in 2006 (Harner et al., 2006). Elevated ozone in the air and its potential impact on the terrestrial ecosystem have attracted much attention in 2006. For example, Ramo et al. (2006) examined the impact of ozone and elevated $\mathrm{CO}_{2}$ on grassland ecosystem, and Thomas et al. (2006) investigated the effect of ozone and nitrogen load on the growth and nutrient uptake by beech trees. Other topics include emission of greenhouse gases from terrestrial ecosystem,

Table 2

Ranking of scientists contributing to Environmental Pollution in 2006

\begin{tabular}{lll}
\hline Number of papers & Author & Country \\
\hline 7 & Mench, M. & France \\
& Tao, S. & China \\
6 & Tanabe, S. & Japan \\
5 & Covaci, A. & Belgium \\
& Jones, K.C. & UK \\
Liu, W.X. & China \\
Van Gronsveld, J. & Belgium \\
Wong, M.H. & China \\
4 & Harner, T. & UK \\
Holoubek, I. & UK \\
Klanova, J. & Czech Republic \\
& Lam, P.K.S. & China \\
& Luo, Y.M. & China \\
Renella, G. & Italy \\
& Ruttens, A. & Belgium \\
Schepens, P. & Belgium \\
& Semple, K.T. & UK \\
Xing, B.S. & USA \\
Zhu, Y.G. & China \\
\hline
\end{tabular}


health impact of air pollution, air-vegetation exchange of POPs, etc.

Methods of sampling, monitoring and risk assessment have also received considerable attention in 2006. There are about 30 papers published in 2006 that are directly related to methods for sampling and characterization. Studies on this subject include passive sampler for air and water (Vrana et al., 2006; Harner et al., 2006), biomimetic methods for soil and water (Ehlers and Loibner, 2006), bioindicators (such as lichen, biomarkers and biosensors) for toxic substances (Dawson et al., 2006; Magni et al., 2006).

In conclusion, 2006 was a very successful year for Environmental Pollution. When accessed on 29, July 2007 to the ISI database, 450 citations have already been attracted by the papers published in 2006.

\section{References}

Dawson, J.J.C., Campbell, C.D., Towers, W., Cameron, C.M., Paton, G.I., 2006. Linking biosensor responses to $\mathrm{Cd}, \mathrm{Cu}$ and $\mathrm{Zn}$ partitioning in soils. Environmental Pollution 142, 493-500.

Ehlers, G.A.C., Loibner, A.P., 2006. Linking organic pollutant (bio)availability with geosorbent properties and biomimetic methodology: a review of geosorbent characterisation and (bio)availability prediction. Environmental Pollution 141, 494-512.

Harner, T., Pozo, K., Gouin, T., Macdonald, A.-M., Hung, H., Cainey, J., Peters, A., 2006. Global pilot study for persistent organic pollutants (POPs) using PUF disk passive air samplers. Environmental Pollution 144, 445-452.

Isosaari, P., Hallikainen, A., Kiviranta, H., Vuorinen, P.J., Parmanne, R., Koistinen, J., Vartiainen, T., 2006. Polychlorinated dibenzo- $p$-dioxins, dibenzofurans, biphenyls, naphthalenes and polybrominated diphenyl ethers in the edible fish caught from the Baltic Sea and lakes in Finland. Environmental Pollution 141, 213-225.

Jaspers, V.L.B., Covaci, A., Voorspoels, S., Dauwe, T., Eens, M., Schepens, P., 2006. Brominated flame retardants and organochlorine pollutants in aquatic and terrestrial predatory birds of Belgium: levels, patterns, tissue distribution and condition factors. Environmental Pollution $139,340-352$.

Leung, H.M., Ye, Z.H., Wong, M.H., 2006. Interactions of mycorrhizal fungi with Pteris vittata (As hyperaccumulator) in As-contaminated soils. Environmental Pollution 139, 1-8.

Magni, P., De Falco, G., Falugi, C., Franzoni, M., Monteverde, M., Perrone, E., Sgro, A., Bolognesi, C., 2006. Genotoxicity biomarkers and acetylcholinesterase activity in natural populations of Mytilus galloprovincialis along a pollution gradient in the Gulf of Oristano (Sardinia, western Mediterranean). Environmental Pollution 142, 65-72.

Mench, M., Renella, G., Gelsomino, A., Landi, L., Nannipieri, P., 2006. Biochemical parameters and bacterial species richness in soils contaminated by sludge-borne metals and remediated with inorganic soil amendments. Environmental Pollution 144, 24-31.

Ramo, K., Kanerva, T., Nikula, S., Ojanpera, K., Manninen, S., 2006. Influences of elevated ozone and carbon dioxide in growth responses of lowland hay meadow mesocosms. Environmental Pollution 144, 101-111.

Ren, H.M., Wang, J.D., Zhang, X.L., 2006. Assessment of soil lead exposure in children in Shenyang, China. Environmental Pollution 144, 327-335.

Regvar, M., Vogel-Mikus, K., Kugonic, N., Turk, B., Batic, F., 2006. Vegetational and mycorrhizal successions at a metal polluted site: indications for the direction of phytostabilisation? Environmental Pollution 144, 976-984.

Skovlund, G., Damgaard, C., Bayley, M., Holmstrup, M., 2006. Does lipophilicity of toxic compounds determine effects on drought tolerance of the soil collembolan Folsomia candida? Environmental Pollution 144, 808-815.

Thomas, G.O., Wilkinson, M., Hodson, S., Jones, K.C., 2006. Organohalogen chemicals in human blood from the United Kingdom. Environmental Pollution 141, 30-41.

Vogel-Mikus, K., Pongrac, P., Kump, P., Necemer, M., Regvar, M., 2006. Colonisation of a $\mathrm{Zn}, \mathrm{Cd}$ and $\mathrm{Pb}$ hyperaccumulator Thiaspi praecox Wulfen with indigenous arbuscular mycorrhizal fungal mixture induces changes in heavy metal and nutrient uptake. Environmental Pollution 139, 362-371.

Vrana, B., Mills, G.A., Dominiak, E., Greenwood, R., 2006. Calibration of the Chemcatcher passive sampler for the monitoring of priority organic pollutants in water. Environmental Pollution 142, 333-343. 